\title{
Current management of obsessive and phobic states
}

This article was published in the following Dove Press journal:

Neuropsychiatric Disease and Treatment

29 September 2011

Number of times this article has been viewed

\author{
Serena Goljevscek' \\ Livia A Carvalho \\ 'Psychiatric Clinic, University of \\ Udine, Udine, Italy; ${ }^{2}$ Health Science \\ Research Centre, Department of Life \\ Sciences, Roehampton University, \\ London, UK
}

\begin{abstract}
Obsessional states show an average point prevalence of $1 \%-3 \%$ and a lifetime prevalence of $2 \%-2.5 \%$. Most treatment-seeking patients with obsessions continue to experience significant symptoms after 2 years of prospective follow-up. A significant burden of impairment, distress, and comorbidity characterize the course of the illness, leading to an increased need for a better understanding of the nature and management of this condition. This review aims to give a representation of the current pharmacological and psychotherapeutic strategies used in the treatment of obsessive-compulsive disorder. Antidepressants (clomipramine and selective serotonin reuptake inhibitors) are generally the first-line choice used to handle obsessional states, showing good response rates and long-term positive outcomes. About $40 \%$ of patients fail to respond to selective serotonin reuptake inhibitors. So far, additional pharmacological treatment strategies have been shown to be effective, ie, administration of high doses of selective serotonin reuptake inhibitors, as well as combinations of different drugs, such as dopamine antagonists, are considered efficacious and well tolerated strategies in terms of symptom remission and side effects. Psychotherapy also plays an important role in the management of obsessive-compulsive disorder, being effective for a wide range of symptoms, and many studies have assessed its long-term efficacy, especially when added to appropriate pharmacotherapy. In this paper, we also give a description of the clinical and psychological features likely to characterize patients refractory to treatment for this illness, with the aim of highlighting the need for greater attention to more patient-oriented management of the disease.
\end{abstract}

Keywords: obsessive-compulsive disorder, phobic disorder, treatment

\section{Introduction}

Obsessions are defined as "intrusive, repetitive thoughts, images or impulses that are unacceptable and/or unwanted and rise to subjective resistance; the necessary and sufficient conditions are intrusiveness, internal attribution and difficulty of control." In addition to their intrusive and disturbing quality, obsessive concerns have traditionally been conceptualized as ego-dystonic (alien to the self). Individuals with obsessive disorder typically engage in repetitive compulsive behaviors or mental processes that cause distress or interfere with functioning, and often avoid those things or situations that trigger their obsessive and/or compulsive behaviors, so avoidance behavior becomes a central feature of the disorder. ${ }^{2}$

Although the Diagnostic and Statistical Manual of Mental Disorders, Fourth Edition (DSM-IV) classifies obsessive-compulsive disorder (OCD) as an anxiety disorder, some clinicians consider it to be a spectrum of related disorders, which includes the somatoform disorders (body dysmorphic disorder and hypochondriasis),
Correspondence: Serena Goljevscek Psychiatric Clinic, University of Udine, Azienda Ospedaliero-Universitaria di Udine, Piazzale Santa Maria della Misericordia I, 33100 Udine, Italy

Tel +390432559284

Fax +390432559 I88

Email seregoly@yahoo.it 
impulse-control disorder, and tic disorders. Anxious and phobic manifestations have been included within the OCD spectrum, but there is an increasing need among psychiatrists for a clear definition of the clinical features and dimensions of symptoms. ${ }^{3}$

\section{Epidemiology}

Epidemiological surveys of obsessional states show an average point prevalence of $1 \%-3 \%$ and a lifetime prevalence of $2 \%-2.5 \%$, with a predominance of female cases. ${ }^{4}$ Most treatment-seeking patients with obsessions continue to experience significant symptoms after 2 years of prospective follow-up. Earlier age at onset, greater severity of symptoms, being older, and male gender seem to be associated with a decreased likelihood of full or partial remission. A significant burden of impairment, distress, and comorbidity characterize the course of the illness. ${ }^{5}$ Suicidal attempts are quite frequent in obsessive patients, thus giving a clear indication of unmet need and the necessity to increase the level of awareness about the nature and management of this condition. ${ }^{6}$

\section{Pathogenesis}

A growing body of evidence supports a role for increased midbrain/basal ganglia dopaminergic neurotransmission, which attenuates the ability of the frontal cortex to suppress affective responses generated in the amygdala. ${ }^{7}$ Many candidate genes have been analyzed to understand the pathophysiological basis of obsessions, with serotonergic, dopaminergic, and glutamatergic genes being the most often implicated. ${ }^{8}$ More recently, a role for glutamatergic hyperactivity has been hypothesized, secondary to a lack of serotoninergic inhibition of the orbitofrontal, thalamic, and striatal areas. ${ }^{9}$

\section{Current treatments}

Many studies have been performed to understand better and improve the therapeutic management of phobic-obsessive disorders. Here we present a review of the treatment strategies proposed so far, with the aim of giving practical and comprehensive information on this topic.

\section{Serotonin reuptake inhibition}

Clomipramine is a tricyclic antidepressant and acts by inhibiting reuptake of norepinephrine and serotonin, but serotonin inhibition is more pronounced. It is clearly recognized that clomipramine has a unique antiobsessional effect as a result of its potent serotonin reuptake inhibition, and this agent has also helped to clarify biological aspects involved in the disorder. ${ }^{10,11}$ Several studies have demonstrated that clomipramine 150-300 $\mathrm{mg}$ /day for 8-16 weeks causes an average decrease of $25 \%-30 \%$ in Y-BOCS scores (a widely used measure administered by clinicians to assesses the severity of obsessive-compulsive symptoms over the previous week). ${ }^{12,13}$ The efficacy of clomipramine compared with selective serotonin reuptake inhibitors (SSRI) has been reviewed thoroughly, providing evidence of equivalent antiobsessional efficacy, with the SSRI nevertheless being better tolerated and having a more favorable side effect profile, so being preferable as first-line treatment. ${ }^{14-16}$

\section{Selective serotonin reuptake inhibition} Paroxetine

Most of the active principals within this pharmacological class have been investigated in the treatment of obsessive disorder and phobic behaviors, and been shown to be efficacious both in the acute and maintenance phases, and well tolerated in terms of side effects. ${ }^{20,33,46,54}$ Several studies have investigated paroxetine in the acute treatment of obsessions. Clinically significant improvements are evident at doses of 20-60 mg/day with respect to depressive symptoms, anxiety, and overall functioning. Moreover, paroxetine shows a wide spectrum of antianxiety effects and can be recommended as first-line therapy in treating comorbidities. ${ }^{17,18}$ Paroxetine was found to reduce symptoms of avoidance associated with phobic-related behaviors and to improve patient quality of life significantly. ${ }^{19}$ Depressive symptoms, which often co-occur, were shown to ameliorate during paroxetine treatment, and such improvement seems to be the result of increased social interaction subsequent to a reduction in fear and avoidance. ${ }^{20}$

The long-term safety and efficacy of paroxetine, as well as its impact on prevention of relapse of obsessive symptoms, have been assessed, showing paroxetine to be effective and generally well tolerated. Doses of at least $40 \mathrm{mg} /$ day are necessary to obtain a good outcome. In addition, long-term treatment can sustain the clinical improvement obtained with short-term treatment, and can prevent recurrence of symptoms without any increase in adverse events.

Significant reduction in disease severity and improvement in phobic states were maintained with continued treatment using paroxetine (up to 36 weeks), showing a reduced risk of relapse, allowing patients to improve their capacity to rebuild social and professional relationships, and leading to a more productive and satisfying life. ${ }^{21}$ 


\section{Fluvoxamine}

The complex pattern of activity of fluvoxamine may account for its efficacy in the treatment of obsessional states, although its pharmacokinetic profile and pattern of side effects may hinder rapid dose escalation. Controlled studies conducted over 6-12 weeks showed a good response to fluvoxamine (dose range 100-300 mg/day). ${ }^{22,23}$ The majority of studies were conducted with clomipramine as the comparator, and the two drugs were shown to be equally effective, with clomipramine being less tolerated due to adverse effects. ${ }^{24,25}$ Social anxiety, avoidance, and phobic symptoms were shown to decrease after 6-8 weeks of fluvoxamine treatment, and continued to improve by week $12 .{ }^{26}$ Long-term treatment (40 weeks) with fluvoxamine in the dose range of $100-300 \mathrm{mg} /$ day was found to correlate with improvement in psychosocial skills, together with improvement of obsessive symptoms. ${ }^{27}$

\section{Escitalopram}

Escitalopram shows high serotonin reuptake selectivity, favorable pharmacokinetics, and comparatively good tolerability, suggesting a potential role in the treatment of obsessional states.$^{28}$ Clinical improvement appears at a dose of $20 \mathrm{mg} /$ day, and escitalopram seems to produce significant benefits in overall disease severity as well as global improvement. ${ }^{29,30}$ Data from a placebo-controlled study showed escitalopram to have good efficacy across several obsessive symptom dimensions, including contamination, symmetry, somatic obsessions, cleaning, checking, and ordering compulsions. ${ }^{31}$

Short-term treatment with escitalopram was found to produce better results than paroxetine in terms of improvement in different phobic symptom dimensions, including social interaction, fears, and assertiveness. Three different doses of the drug $(5,10$, and $20 \mathrm{mg} /$ day $)$ were compared with a fixed dose of paroxetine ( $20 \mathrm{mg}$ /day) during a 12-week trial, with escitalopram showing both greater efficacy and better tolerability. ${ }^{32}$

Escitalopram was shown to be effective in preventing relapse and to be safe and generally well tolerated for the long-term treatment of obsessive states. In a 24-week study, escitalopram $10 \mathrm{mg}$ and $20 \mathrm{mg}$ were both effective for all primary and secondary outcome measures in preventing relapse, and escitalopram's antiobsessional effects, obtained with short-term treatment, was maintained throughout the study period. ${ }^{33}$

A 24-week trial of fixed doses of escitalopram (5, 10, and $20 \mathrm{mg}$ /day) demonstrated its long-term efficacy across various symptom dimensions in a group of patients suffering from phobic avoidance-related states. ${ }^{34}$ A significant reduction in relapses was shown with flexible doses of escitalopram (10-20 mg/day) compared with placebo ( $22 \%$ versus $50 \%)$ in a 24-week relapse prevention study, suggesting that a much longer period of treatment may be necessary to achieve a long-lasting positive outcome. ${ }^{35}$

\section{Fluoxetine}

Fluoxetine has been investigated since 1985, and has been shown to be effective in obsessive disorders at the dose range of 40-60 mg daily. ${ }^{36-38}$ The effects of fluoxetine on different clinical subtypes of OCD have been investigated, showing a significant decrease in symptoms, with greater efficacy for obsessive thoughts and washing compulsions, ${ }^{39}$ as well as improvement in psychosocial functioning and quality of life. ${ }^{40}$ As regards management of phobic symptoms, fluoxetine was shown to be as efficacious as placebo for short-term treatment and in a 24-week maintenance phase both as monotherapy and in association with comprehensive cognitive behavioral therapy. ${ }^{41-43}$ Fluoxetine was shown to be efficacious and safe for preventing relapse of obsessive disorders in patients who responded to its short-term administration. Low overall rates of relapse were evident at the maintenance dose of $40 \mathrm{mg} /$ day, but the $60 \mathrm{mg} /$ day dose seemed to provide greater protection. It was found to have a good safety profile, and adverse effects rarely led to discontinuation of treatment. ${ }^{44}$

\section{Citalopram}

Citalopram has been investigated for its efficacy in the treatment of obsessive disorder, with the highest response rate found at $60 \mathrm{mg} /$ day, together with good tolerability. ${ }^{45}$ It was shown to improve psychosocial functioning, mental and physical health-related quality of life, and delusional as well as depressive symptoms, together with a decrease in obsessional preoccupation, repetitive behavior, and distress. ${ }^{46,47}$ Its efficacy has also been demonstrated in the short-term treatment of phobic anxiety and avoidance behavior. In 8-12-week trials, citalopram at dosages of $20-60 \mathrm{mg}$ /day seemed to produce a positive clinical outcome and to be well tolerated, with $75 \%-86 \%$ of subjects being deemed responders, and no withdrawals due to side effects. ${ }^{48,49}$ Citalopram appears to be efficacious in patients with refractory obsessive disorder who do not respond to other treatments. Moreover, it seems to be a useful strategy when other psychiatric conditions coexist together with obsessions. ${ }^{50}$ Long-term treatment with citalopram was investigated in a large sample of acute patients suffering from phobic avoidance and anxiety-related symptoms of arousal, and citalopram 
20-30 mg/day appeared to be the most effective dosage in terms of clinical improvement. ${ }^{51}$

\section{Sertraline}

Sertraline has been evaluated for its efficacy and safety in obsessional states at dosages of 50-200 mg/day, with positive results..$^{52} \mathrm{~A}$ faster response is achieved with rapid titration of sertraline up to $200 \mathrm{mg} /$ day. The faster the achievement of the full dose, the earlier the relief of OCD symptoms, especially when a rapid response is needed without undue delay. With respect to tolerability, the number of side effects, as well as discontinuation rates, seems to be comparable between fast and slow titration strategies, suggesting that the dosage per se, and not the time to full dose achievement, is important in determining tolerability. ${ }^{53} \mathrm{~A}$ comparative study investigating the efficacy of sertraline versus cognitive behavioral therapy in the short-term treatment of obsessive disorder showed comparable positive outcomes for both treatment in managing symptoms of anxiety and depression, together with improved quality of life. ${ }^{54}$ Sertraline showed significant efficacy, compared with placebo, in the management of phobic-related states, with greater symptom reduction across the domains of anxiety/fearfulness, physiological symptoms, and behavioral avoidance ${ }^{55}$ Clinical improvements in obsessive disorders and phobic behaviors have been achieved by long-term therapy with sertraline, and with a good side effect profile. A 20-week trial with sertraline 50-200 mg/day produced significant improvement, both in work functioning and in social skills, together with high tolerability. ${ }^{56}$ Relapse prevention studies have shown that sertraline significantly ameliorates symptoms of anxiety and avoidance behavior after 24 weeks of treatment. The avoidance dimension was the last to be improved, suggesting that this clinical outcome may require longer-term therapy to overcome well established behavioral patterns. ${ }^{57}$ Sertraline showed lower relapse rates, a better clinical response, and overall improvement in quality of life. ${ }^{58,59}$ High-dose sertraline $(250-400 \mathrm{mg} /$ day $)$ has been assessed in the treatment of patients who have failed to respond to standard doses, showing significant symptom improvement and an adverse event rate similar to that seen at a dosage of $200 \mathrm{mg} /$ day. ${ }^{60}$

\section{Selective noradrenergic-serotonin reuptake inhibition}

Selective noradrenergic-serotonin reuptake inhibitors (SNRI) combine the actions of SSRI with noradrenergic reuptake inhibitors, have a robust effect on serotonin, and do not block $\alpha 1$-adrenergic, cholinergic, or histaminergic receptors, thus showing better tolerability.

\section{Venlafaxine}

Venlafaxine has been found to have efficacy equivalent to that of clomipramine in short-term treatment, but with a more favorable safety profile. ${ }^{61}$ The majority of venlafaxine trials have demonstrated the efficacy of this compound in short-term and medium-term trials and in both treatment-naïve and treatmentresistant obsessive patients. In two double-blind, active comparative studies, venlafaxine was shown to be more effective than paroxetine and clomipramine. Moreover, venlafaxine was shown to be particularly effective in patients who previously did not respond to SSRIs, and was well tolerated. ${ }^{62,63} \mathrm{An}$ appropriate dosage of venlafaxine in the treatment of obsessional states is usually in the range of 150-300 mg/day, although higher doses may sometimes be required. A response may be observed as early as four weeks after beginning treatment, but continued improvement may be noted for up to about 10 weeks. ${ }^{64}$

Flexible doses of venlafaxine extended-release (75-225 mg/day) in the short term produced a significantly greater clinical improvement than placebo in managing phobic-related states, together with a good side effect profile. Most of the adverse events reported were mild to moderate in severity, and were similar to previous data from major depression and general anxiety disorder studies. ${ }^{65,66}$ The long-term efficacy and safety of venlafaxine extended-release at different dosages (75 mg/day and 150-225 mg/day) was assessed in a 6-month trial, showing comparable response and remission rates for both lower and higher doses. ${ }^{67}$

\section{Duloxetine}

Despite growing evidence of good efficacy for duloxetine in the treatment of anxiety disorders, there is a relative lack of data demonstrating its potential efficacy in obsessional states. There are some case reports of obsessive-compulsive patients with comorbid mood or anxiety disorders treated with serotonin reuptake inhibitors at adequate doses for at least 12 weeks and showing a partial response or no response, who were switched to duloxetine up to $120 \mathrm{mg}$ /day with significant clinical improvement, pointing to a role for duloxetine in patients with treatment-resistant OCD. ${ }^{68}$

\section{Antipsychotics}

Although the effectiveness of SSRI has been well established in the treatment of obsessive disorders, about $40 \%$ of patients fail to respond to these agents, with only a minority experiencing full remission of symptoms. ${ }^{69,70}$ For such patients, additional pharmacological strategies, such as higher doses of SSRI, as well as combination treatment with dopamine antagonists, have been investigated in several studies. ${ }^{71,72}$ 
Dopamine antagonists have been shown to be the most effective agents for an augmentation strategy, with the atypical antipsychotics being better tolerated than traditional neuroleptics. ${ }^{73}$ The synergistic action of $5-\mathrm{HT}_{2 \mathrm{~A}}$ receptor blockade by atypical agents, with the simultaneous inhibition of 5-HT uptake by SSRI, leads to greater therapeutic efficacy. Given the similar clinical efficacy of the SSRI in obsessional states, the variability in response could lie in their pharmacological effects on the 5-HT transporter, as well as on norepinephrine and dopamine transporters. These subtle differences between the SSRI in their 5-HT, norepinephrine, and dopamine transporter affinities might account for their different therapeutic effects when used in combination with various antipsychotics as an augmentation strategy. ${ }^{74}$ To date, there have been a number of studies conducted using different atypical compounds in order to understand better the therapeutic value of augmentation strategies, their convenient use, and their safety in obsessional states.

\section{Risperidone}

Addon risperidone therapy in patients with refractory obsessive symptoms has been studied by many investigators. ${ }^{75-77}$ In a comparative study of risperidone $1 \mathrm{mg} /$ day and haloperidol $2 \mathrm{mg} /$ day, the atypical antipsychotic was found to improve obsessive symptoms, with a better side effect profile. In fact, in this study, none of the risperidone-treated subjects discontinued treatment because of adverse events, although its potential long-term effects were not considered. ${ }^{78}$ Risperidone $1-3 \mathrm{mg}$ /day was found to be as efficacious and well tolerated as olanzapine $2.5 \mathrm{mg} /$ day in patients failing to respond to the maximum tolerated daily dose of SSRI for at least 12 weeks. Both treatment groups showed a marked and significant improvement in obsessions and compulsions over the eight-week augmentation period, with the same response rates across time. Tolerability was comparable between the treatment groups, and differences only emerged when considering single adverse events, and showed that risperidone was more likely to be associated with akathisia and amenorrhea. ${ }^{79}$

\section{Aripiprazole}

Aripiprazole is a partial agonist at dopamine $\mathrm{D} 2$ and 5- $\mathrm{HT}_{1 \mathrm{~A}}$ receptors, and also acts as a $5-\mathrm{HT}_{2 \mathrm{~A}}$ receptor antagonist. These dopamine-5-HT stabilizing properties might be of therapeutic value in obsessive disorders. There have been two case reports demonstrating the effectiveness of augmentation using aripiprazole $20 \mathrm{mg} /$ day for severe obsessive symptoms, showing a significant clinical improvement at 6-12 weeks, together with long-lasting therapeutic effects. ${ }^{80}$ In another case report of a refractory obsessive patient (previously treated with high doses of clomipramine and sertraline, augmented with clonazepam, low doses of risperidone, and then olanzapine, with no beneficial effects), long-term improvement was evident with the addition of aripiprazole $7.5 \mathrm{mg} /$ day ${ }^{81}$

\section{Olanzapine}

Case reports and augmentation trials have suggested a role for olanzapine in the treatment of refractory obsessive disorders. ${ }^{82,83}$ An augmentation strategy using olanzapine at a low dose of $5 \mathrm{mg} /$ day was assessed in patients refractory to a high dosage of fluvoxamine ( $300 \mathrm{mg} /$ day) and in obsessive patients with an associated schizotypal personality disorder. At the endpoint, $43.5 \%$ of patients experienced significant symptom improvement; full response was achieved after 2 months, with no discontinuations, despite a $39.1 \%$ weight gain among responders. Good tolerability was evident in both groups, with mild to moderate side effects. ${ }^{84}$ Olanzapine was found to induce greater symptom improvement during short-term treatment of refractory obsessive symptoms at the higher dose of $20 \mathrm{mg} /$ day, with ongoing good tolerability. ${ }^{85}$

\section{Quetiapine}

Open studies and case reports have evaluated the efficacy of quetiapine as addon therapy in obsessional states. ${ }^{86,87}$ In OCD patients refractory to at least two SSRI trials, quetiapine $200 \mathrm{mg}$ /day was shown to be significantly more efficacious than SSRI monotherapy in reducing obsessive symptoms, with $40 \%$ of patients rated as responders. The response appeared to occur relatively rapidly and seemed to be especially promising in patients with severe obsession. ${ }^{88}$ Another placebo-controlled study evaluated the efficacy of quetiapine in addition to citalopram in treatment-naïve obsessive patients. This trial was the first to assess the efficacy of quetiapine as addon medication to SSRI in nonrefractory patients, showing good primary outcome rates, with $69 \%$ of patients responding positively. ${ }^{89}$

A pooled study of all available placebo-controlled quetiapine addon trials was performed to assess treatment outcomes in a large sample of obsessive patients and to evaluate the impact of type and dose of SSRI required for efficacy. In a sample of 102 patients, the investigators found a significantly superior response in the quetiapine addon group compared with the placebo group. The best response was achieved with the combination of clomipramine, fluoxetine, and fluvoxamine. ${ }^{74}$ 


\section{Psychotherapy}

Behavioral and cognitive therapies have been found to be effective in the treatment of obsessive disorder in several studies. ${ }^{90,91}$ In an effort to maximize the treatment effect in clinical practice, cognitive behavioral therapy is frequently combined with antidepressant therapy. A review of controlled trials and a meta-analysis that involved cognitive and/or behavioral treatment for obsessional states confirmed that both exposure and response prevention and cognitive therapy are effective methods for the treatment of obsessions and compulsions in children, adolescents, and adults. ${ }^{92}$

Both psychotherapy and medication have some disadvantages when considered separately. Many patients show poor motivation and adherence with psychotherapy as well as drug treatment. In clinical trials, up to $25 \%$ of patients refuse to engage in behavioral therapy, $13 \%-17 \%$ discontinue it prematurely, ${ }^{93}$ and $10 \%-30 \%$ of patients fail to respond. ${ }^{94}$

Biondi and Picardi assessed the long-term effectiveness of integrated treatment (medication plus cognitive behavioral psychotherapy) compared with medication alone in 20 consecutive patients with OCD who achieved remission or marked improvement after treatment with clomipramine or SSRI. Eight of 10 patients treated with medication alone relapsed versus one relapse in the integrated treatment group. It thus seems that an appropriate combination of psychotherapy and medication might be more effective than either treatment alone on the long-term course of the disease. Starting medication before psychotherapy and gradually discontinuing it before psychotherapy ends appears to be the best strategy, because medication might facilitate subsequent engagement of the patient in psychotherapy and help to increase self-efficacy. ${ }^{95}$

O'Connor et al compared the outcomes of therapy in four comparable groups of obsessive patients receiving four different treatments, ie, standardized medication only, placebo only, cognitive behavioral therapy only, and cognitive behavioral therapy following individualized medication. The results showed that all the active treatments improved the symptomatology, with a more specific antiobsessional effect of cognitive behavioral therapy than medication only. The groups receiving cognitive behavioral therapy had a significant decrease in obsessional doubts, anticipated consequences, self-efficacy in resisting ritual behavior, and degree of conviction in the need to perform the ritual, thus resulting in better cognition. ${ }^{96}$

Cognitive behavioral therapy, involving cognitive restructuring and exposure to feared and avoided situations, has been found to be an efficacious therapy for obsession-related phobic behaviors. ${ }^{42,97,98}$ The core of psychotherapy focuses on the distorted perceptions and beliefs which usually trigger physical, behavioral, and cognitive symptoms producing discomfort, reinforcing a negative self-image, and increasing avoidant attitudes. Cognitive behavioral therapy seems to work in both the acute and maintenance phases of treatment. Its effects on durability of gains after discontinuation have been assessed in responders to either phenelzine or group cognitive behavioral therapy, the latter being more likely to maintain a response after the end of treatment. ${ }^{99}$

The same results were obtained in another trial showing combined treatment with cognitive behavioral group therapy and phenelzine to exert a truly additive and synergistic effect in the management of phobic symptoms. ${ }^{100}$ Combination therapy seems to be a useful strategy to manage both the clinical and social aspects of obsessive and phobic behaviors because it alleviates acute disturbing symptoms and enables patients to develop better self-awareness.

\section{Treatment of refractory obsessive-compulsive disorder}

Up to $40 \%-60 \%$ of patients with OCD do not respond to standard treatments, and develop a significant burden of disability and mordibity. ${ }^{101}$ Patients often express poor motivation or adherence towards both psychotherapy, with $25 \%$ refusing behavioral therapy, ${ }^{102,103} 13 \%-17 \%$ discontinuing it prematurely, ${ }^{90-93}$ and $10 \%-30 \%$ showing an unsatisfactory response, ${ }^{94,103}$ with lack of motivation and poor compliance. Up to $20 \%$ of patients do not want to take drugs and $20 \%-25 \%$ stop medication prematurely. ${ }^{90-93}$ Moreover, $37 \%-63 \%$ of patients in clinical trials do not respond to treatment. ${ }^{93}$ Follow-up studies have highlighted that discontinuing medication leads to symptom exacerbation or relapse in 32\%-89\% of patients, even after long-term treatment and drug-tapering, and there is often a high risk of resistance to the drug used previously. ${ }^{104,105}$

Understanding the reason for early treatment interruption is an important step in identifying more effective therapeutic strategies. Thus, clarifying which factors are linked with noncompliance could enable the clinician to recognize the treatment option which best suits a particular patient and provide the greatest chance of compliance. A study by Diniz et al was performed to investigate the clinical correlates of early treatment discontinuation among OCD patients. Their major finding was that anxiety and somatization disorders were closely related to treatment discontinuation in their group of patients, who were treated only with SSRI. These authors argued that this could be connected with the initial 
worsening of anxiety symptoms induced by SSRI medication which might push more vulnerable patients to early cessation of medication. They also observed better outcomes, in terms of compliance, with an increased frequency of consultations in the initial phase of their study. ${ }^{106}$

Both psychotherapy and medication differ in their strengths and weaknesses, thus it seems that a proper combination of the two might be more appropriate and effective than either treatment alone. ${ }^{95}$ In many trials, combining the two strategies has been found to be more useful and clinically superior to medication or psychotherapy alone. ${ }^{11,107}$ Sapana et al performed an interesting study exploring treatment preferences in OCD patients, and showed that combined therapy (psychotherapy plus medication) appears to be the most preferred choice overall. There are several factors that may influence the treatment choices, ie, past positive or negative experiences, complexity of the procedure, patient attitudes, and self-education. ${ }^{108}$ It has emerged from several studies that discussing treatment preferences improves the therapeutic alliance and facilitates better uptake of treatment recommendations. ${ }^{109,110}$ Important areas to discuss include past treatment experiences, beliefs, or concerns about medications/psychotherapy, and practical issues, such as duration of therapy, side effects, and access to trained OCD providers.

Many factors have been linked with poor response to treatment, ie, sexual or religious obsessions, ${ }^{111}$ hoarding, ${ }^{112}$ poor insight, ${ }^{113}$ psychiatric comorbidity, ${ }^{114}$ and early onset of the disease. ${ }^{115}$ The sexual and religious dimensions have been found to be an important issue in terms of treatment response. Some authors have shown a link between sexual and religious obsessive-compulsive symptoms and higher rates of refractoriness and less favorable outcomes, both in pharmacological and psychotherapy trials. ${ }^{11-116}$ Social and cultural aspects should not be underestimated in this regard. Social contexts and cultural background play an important role in establishing values and beliefs. Thus, some sexual and religious thoughts can be almost unbearable for patients with a strong inner moral structure, and their obsessive quality can be experienced as an expression of their high moral values rather than as mental distress. This could lead to development of feelings of guilt and depressive symptoms, which enhance and worsen OCD and negatively impact the response to treatment.

A study by Mataix-Cols et al investigated the degree of response to treatment using a series of clinical behavioral therapy trials in OCD outpatients. Patients with hoarding characteristics seemed to have more difficulty than other patients in complying with behavioral therapy, ${ }^{116}$ and this finding is consistent with those of several studies. Hoarding patients often lack insight into their problems, are ego-syntonic with their behaviors, and do not recognize them as absurd, disabling, and time-consuming. Clinically, these patients are passive about treatment, endlessly delaying their homework assignments. ${ }^{117}$ Some studies on this issue have shown that these patients also respond less well to pharmacotherapy. ${ }^{112-118}$ Thus, it seems important to develop specific programs for hoarders, with different cognitive behavioral interventions, including training in decision-making, exposure and response prevention, and cognitive restructuring, together with appropriate pharmacological therapy targeted to reduce and downsize the burden of symptoms. ${ }^{126,127}$ Moreover, group treatment has been suggested to be superior to individual therapy in the management of hoarding behaviors, because sharing suffering and feeling part of a "common story" might enhance motivation for change. ${ }^{119}$

The course of obsessive-compulsive symptoms has a role in defining the response to treatment. A chronic course of disease is more likely in refractory patients, and has been demonstrated by some authors. ${ }^{120,121}$ In addition, chronic patients seem to have more severe symptoms from the outset, which can lead to worse impairment of emotional, social, and professional functioning, thus increasing the risk of a less favorable response to treatment. ${ }^{120}$

Identifying subgroups of OCD patients appears to be an important issue for understanding the pathophysiological mechanisms of the disease better and developing more specialized treatment strategies. The OCD subtype called "with poor insight," as defined in the Diagnostic and Statistical Manual of Mental Disorders, Fourth Edition, includes subjects who do not recognize the excessiveness of their symptoms during the course of a current episode; the rate of this subtype varies from $15 \%$ to $36 \%$, as showed in several studies. ${ }^{122-124}$ Poor insight appears to be related to more severe OCD symptoms, ${ }^{122,123}$ early onset of the disease, and a longer duration of illness, ${ }^{123}$ and is a feature which frequently characterizes OCD patients with an associated schizotypal personality disorder. ${ }^{123,124}$ Moreover, overvalued obsessional beliefs have been shown to affect the response to individual and group therapy, ${ }^{125,126}$ perhaps due to lack of cognitive engagement by these patients. Instead, less homogenous results have been reported for the relationship between poor insight and response to medication; some researchers found a worse treatment response in this group of patients at both 12 weeks and 6 months after an SSRI trial. ${ }^{113,122}$ A recent study by Catapano et al assessed the insight dimension in a group of OCD patients using a standardized instrument 
called the Brown Assessment of Beliefs Scale, which covers a range of dimensions, such as beliefs, fixed ideas, insight, perception of others' beliefs, and ideas of reference, aims to detect and focus on the patient's dominant belief, concern, or delusion, and to estimate its impact on the patient's life. The results obtained by Catapano et al showed significant impairment of critical skills in patients with poor insight, together with a strong and firm connection to their obsessive ideas and compulsive behaviors, experienced as right and unquestionable. Moreover, the poor insight group was characterized by more severe symptomatology, an earlier onset of illness, and a higher rate of comorbidity with schizotypal personality disorder. ${ }^{127}$ This latter finding is in accordance with previous studies exploring this issue, and suggests an interaction between OCD and psychotic spectrum disorders. Some authors have hypothesized that OCD patients with poor insight and comorbid schizotypal personality may be considered as a separate subgroup with specific clinical features, worse treatment response rates and prognosis, and a close connection to schizophrenia-related disorders. ${ }^{124-128}$ Paranoid ideation may affect a patient's ability to understand fully the lack of sense in their obsessions and rituals, and it may also have bad implications in terms of treatment compliance and response. On the other hand, SSRI therapy in OCD patients has been shown to ameliorate their insight, along with improvement in obsessive symptomatology. According to this finding, we might consider insight a dynamic phenomenon, affected by different variables, such as clinical condition, personality type, and affective status. ${ }^{124}$ In a study by Ravi Kishore et al, patients with poor insight were more likely to suffer from a depressive disorder, the insight score being closely correlated with this comorbidity. ${ }^{129}$ This finding seems to be consistent with previous data showing high rates of depression among OCD patients with poor insight. ${ }^{131}$ It has yet to be clarified whether depression contributes to poor insight or if it is more a consequence of a more severe form of the disease. Some authors have suggested that major depression might act on obsessions, transforming them into overvalued ideas which are difficult to criticize. From this perspective, improvement in depressive symptoms appears to be a necessary step towards achieving a positive outcome, in terms of clinical recovery and global functioning. ${ }^{131}$

The therapeutic implications for OCD patients with poor insight include lower rates of response, seen in both pharmacological trials and with psychotherapy. Accordingly, some authors have proposed that this subgroup of patients is biologically different in terms of neurotransmission pathways, ie, these patients basically have a form of dopaminergic dysregulation. ${ }^{132}$ Clinicians have often treated these patients with antipsychotics in addition to SSRI, but to date no study has assessed whether insight predicts response to augmentation with antipsychotics in OCD. In the study by Catapano et al, they found that only $45 \%$ of OCD patients with poor insight showed a positive clinical outcome after the addition of low doses of neuroleptic to established SSRI therapy. ${ }^{127}$

Finally, an important issue that is closely related to a favorable course of OCD is family functioning. A change in family functioning due to a patient's OCD behaviors may be seen in the so-called "family accommodation index." It is very important to remind a patient's relatives that performing rituals together with the patient or facilitating them reinforces the symptoms. Often, an overinvolved, frustrated, or rejecting attitude of family members increases the patient's stress and worsens symptoms. There are some data showing that hostility, emotional overinvolvement, and criticism expressed by the family can be reflected in treatment outcomes, especially with cognitive behavioral therapy. Ferrao et al have provided evidence to support this notion, showing that OCD affecting family function is associated with a less favorable response to treatment, both pharmacological and psychotherapeutic. ${ }^{120}$ Therefore, it seems important to pay attention to the patient's family context in order to identify potential maladaptive behaviors which could affect the course of the disease, as well as the response to treatment. Social and family approaches have an essential therapeutic role, and should aim to affect the social, educational, and occupational functioning of the individual in a positive way.

\section{Conclusion}

Plenty of work has been done to improve the management of obsessive and phobic states. Despite the development of newer and safer treatment options, there are still a considerable number of patients who continue to bear a heavy burden of disability, silently accepting impairment in their quality of life, due to the insidious and chronic nature of these diseases. The first step towards a more effective therapeutic approach involves careful assessment of the symptoms expressed by the patient in order to make as precise a diagnosis as possible. Partial remission of symptoms and high relapse rates suggest the need to consider obsessive and phobic disorders in a dimensional rather than a categorical way, to identify patients' real needs better, and then implement specific and patient-oriented treatment strategies. Reviewing current therapies in the management of these disorders has allowed us to think over some points. A change in the approach towards obsessive disease, considered as a spectrum of disorders, 
provides a greater insight into its clinical expression, paying more attention to its psychopathological core, and the need to focus not only on the acute phase of the illness, but also on rehabilitation. The high degree of disability, which involves different aspects of patients' lives, social isolation, together with psychiatric comorbidities, increase the burden of pain and anguish, so the aim of treatment should be achievement of global and long-lasting recovery in order to enable patients to achieve a better quality of life.

\section{Disclosure}

The authors report no conflicts of interest in this work.

\section{References}

1. Rachman S, Hodgson R. Obsessions and Compulsions. Hillsdale, NJ: Prentice- Hall; 1980.

2. Bartz JA, Hollander E. Is obsessive-compulsive disorder an anxiety disorder? Prog Neuropsychopharmacol Biol Psychiatry. 2006;30:338-352.

3. Fornaro M, Gabrielli F, Alabano C, et al. Obsessive-compulsive disorder and related disorders: A comprehensive survey. Ann Gen Psychiatry. 2009;18:8-13.

4. Rodrigues Torres A, Pereira Lima MC. Epidemiology of obsessive-compulsive disorder: A review. Rev Bras Psiquiatr. 2005; 27:237-242.

5. Eisen JL, Pinto A, Mancebo MC, Dyck IR, Orlando ME, Rasmussen SA. A 2-year prospective follow-up study of the course of obsessivecompulsive disorder. J Clin Psychiatry. 2010;71:1033-1039.

6. Rodrigues Torres A, Prince MJ, Bebbington PE, et al. Obsessivecompulsive disorder: Prevalence, comorbidity, impact, and helpseeking in the British national psychiatric morbidity survey of 2000 . Am J Psychiatry. 2005;163:1978-1985.

7. Denys D, Zohar J, Westenberg HGM. The role of dopamine in obsessive-compulsive disorder: Preclinical and clinical evidence. J Clin Psychiatry. 2004;14:11-17.

8. Nicolini H, Arnold P, Nestadt G, Lanzagorta N, Kennedy JL. Overview of genetics and obsessive-compulsive disorder. Psychiatry Res. 2008;170:7-15.

9. Goddard AW, Shekhar A, Whiteman AF, McDougle CJ. Serotoninergic mechanisms in the treatment of obsessive-compulsive disorder. Drug Discov Today. 2008;13:325-332.

10. Clomipramine Collaborative Group. Clomipramine in the treatment of patients with obsessive-compulsive disorder. Arch Gen Psychiatry. 1991;48:730-738.

11. Marks IM, Stern RS, Mawson D, Cobb J, McDonald R. Clomipramine and exposure for obsessive-compulsive rituals. $\mathrm{Br} J$ Psychiatry. 1980;136:1-25.

12. Foa EB, Liebowitz MR, Kozak MJ, et al. Randomized, placebocontrolled trial of exposure and ritual prevention, clomipramine and their combination in the treatment of obsessive-compulsive disorder. Am J Psychiatry. 2005;162:151-161.

13. Katz RJ, DeVeaugh-Geiss T, Landau P. Clomipramine in obsessivecompulsive disorder. Biol Psychiatry. 1990;28:401-414.

14. Bisserbe JC, Lane RM, Flament MF; Franco-Belgian OCD Study Group. A double-blind comparison of sertraline and clomipramine in outpatients with obsessive-compulsive disorder. Eur Psychiatry. 1997; 12:82-93.

15. Freeman CP, Trimble MR, Deakin JF, Stokes TM, Ashford JJ. Fluvoxamine versus clomipramine in the treatment of obsessivecompulsive disorder: A multicentre, randomized, double-blind, parallel group comparison. J Clin Psychiatry. 1994;55:301-305.
16. Koran LM, McElroy SL, Davidson JRT, Rasmussen SA, Hollander E, Jenila MA. Double-blind comparison of fluvoxamine and clomipramine in obsessive-compulsive disorder in the United States. Eur Neuropsychopharmacol. 1995;5:371.

17. Hollander E, Allen A, Steiner M, et al. Acute and long-term treatment and prevention of relapse of obsessive-compulsive disorder with paroxetine. J Clin Psychiatry. 2003;64:1113-1121.

18. Saxena S, Brody AL, Maidment KM, Baxter LR, Jr. Paroxetine treatment of compulsive hoarding. J Psychiatr Res. 2007;41:481-487.

19. Stein MB, Liebowitz MR, Lydiard RB, Pitts CD, Bushnell W, Gergel I. Paroxetine treatment of generalized social phobia (social anxiety disorder): A randomized controlled trial. JAMA. 1998;280:708-713.

20. Dempsey JP, Randall PK, Thomas SE, Book SW, Carrigan MH. Treatment of social anxiety with paroxetine: Mediation of changes in anxiety and depression symptoms. Compr Psychiatry. 2009;50: 135-141.

21. Stein DJ, Versiani M, Hair T, Kumar R. Efficacy of paroxetine for relapse prevention in social anxiety disorder: A 24-week study. Arch Gen Psychiatry. 2002;59:1111-1118.

22. Ordacgi L, Mendlowicz MV, Fontenelle LF. Management of obsessivecompulsive disorder with fluvoxamine extended release. Neuropsychiatr Dis Treat. 2009;5:301-308.

23. Koran LM, Bromberg D, Hornfeldt CS, Shepski JC, Wang S, Hollander E. Extended-release fluvoxamine and improvements in quality of life in patients with obsessive-compulsive disorder. Compr Psychiatry. 2010;51:373-379.

24. Mundo E, Maina G, Uslenghi C. Multicenter, double-blind, comparison of fluvoxamine and clomipramine in the treatment of obsessivecompulsive disorder. Int Clin Psychopharmacol. 2000;15:69-76.

25. Milanfranchi A, Ravagli S, Lensi P, Marazziti D, Cassano GB A double-blind study of fluvoxamine and clomipramine in the treatment of obsessive-compulsive disorder. Int Clin Psychopharmacol. 1997; 12:131-136.

26. Stein MB, Abby J, Fyer MD, Davidson JRT, Pollack MH, Wiita B. Fluvoxamine treatment of social phobia (social anxiety disorder): A double-blind, placebo-controlled study. Am J Psychiatry. 1999;56:756-760.

27. Ravizza L, Barzega G, Bellino S. Drug treatment of obsessivecompulsive disorder (OCD): Long-term trial with clomipramine and selective serotonin reuptake inhibitors (SSRIs). Psychopharmacol Bull. 1996;32:167-173.

28. Hedges DW, Woon FLM. An emerging role for escitalopram in the treatment of obsessive-compulsive disorder. Neuropsychiatr Dis Treat. 2007;3:455-461.

29. Zohar J. Escitalopram in the treatment of obsessive-compulsive disorder. Exper Rev Neurother. 2008;18:455-461.

30. Stein DJ, Andersen EW, Tonnoir B, Fineberg N. Escitalopram in obsessive-compulsive disorder: A randomized, placebo-controlled paroxetine-referenced, fixed-dose, 24-week study. Curr Med Res Opin. 2007;23:701-11.

31. Stein DJ, Carey PD, Lochner C, Seedat S, Fineberg N, Andersen EW. Escitalopram in obsessive-compulsive disorder: Response of symptom dimensions to pharmacotherapy. CNS Spectrum. 2008;13:492-498.

32. Lader M, Stender K, Bürger V, Nil R. Efficacy and tolerability of escitalopram in 12 and 24-week treatment of social anxiety disorder: Randomized, double-blind, placebo-controlled, fixed-dose study. Depress Anxiety. 2004;19:241-248.

33. Fineberg NA, Tonnoir B, Lemming O, Stein DJ. Escitalopram prevents relapse of obsessive-compulsive disorder. Eur Neuropsychopharmacol. 2007; 17:430-439.

34. Stein DJ, Andersen EW, Lader M. Escitalopram versus paroxetine for social anxiety disorder: An analysis of efficacy for different symptom dimension. Eur Neuropsychopharmacol. 2006;16:33-38.

35. Montgomery SA, Nil R, Dürr-Pal N, Loft H, Boulenger JP. A 24-week randomized, double-blind, placebo-controlled study of escitalopram for the prevention of generalized social anxiety disorder. J Clin Psychiatry. 2005;66:1270-1278. 
36. Montgomery SA, McIntyre A, Osterheider M, et al. A double-blind, placebo-controlled study of fluoxetine in patients with DSM-III-R obsessive-compulsive disorder. The Lilly European OCD Study Group. Eur Neuropsychopharmacol.1993;3:143-152.

37. Bergeron R, Ravindran AV, Chaput Y, et al. Sertraline and fluoxetine treatment of obsessive-compulsive disorder: Results of a double-blind, 6-months treatment study. J Clin Psychopharmacol. 2002;22:148-154.

38. Tollefson GD, Rampey AH, Potvin JH, et al. A multicenter investigation of fixed dose fluoxetine in the treatment of obsessive-compulsive disorder. Arch Gen Psychiatry. 1994;51:559-567.

39. Farnam A, Goreishizadeh MA, Farhang S. Effectiveness of fluoxetine on various subtypes of obsessive-compulsive disorder. Arch Iran Med. 2008;11:522-525.

40. Phillips KA, Rasmussen SA. Change in psychosocial functioning and quality of life of patients with body dysmorphic disorder treated with fluoxetine: Placebo-controlled study. 2004;45:438-444.

41. Kobak KA, Greist JH, Jefferson JW, Katzelnick DJ. Fluoxetine in social phobia: A double-blind, placebo-controlled pilot study. J Clin Psychopharmacol. 2002;22:257-262.

42. Clark DM, Ehiers A, McManus F, et al. Cognitive therapy vs fluoxetine in generalized social phobia: A randomized placebo-controlled trial. J Consult Clin Psychol. 2003;71:1058-1067.

43. Davidson JRT, Foa EB, Huppert JD, et al. Fluoxetine, comprehensive cognitive behavioral therapy and placebo in generalized social phobia. Arch Gen Psychiatry. 2004;61:1005-1013.

44. Romano S, Goodman W, Tamura R, Gonzales J. Long-term treatment of obsessive-compulsive disorder after an acute response: A comparison of fluoxetine versus placebo. J Clin Psychopharmacol. 2001;21:46-52.

45. Montgomery SA, Kasper S, Stein DJ, Bang Hedegaard K, Lemming OM. Citalopram $20 \mathrm{mg}, 40 \mathrm{mg}$ and $60 \mathrm{mg}$ are all effective and well tolerated compared with placebo in obsessive-compulsive disorder. Int Clin Psychopharmacol. 2001;16:75-86.

46. Phillips KA, Najjar F. An open-label study of citalopram in body dysmorphic disorder. J Clin Psychiatry. 2003;64:715-720.

47. Koran LM, Chuong HW, Bullock KD, Smith SC. Citalopram for compulsive shopping disorder: An open-label study followed by double-blind discontinuation. J Clin Psychiatry. 2003;64:793-798.

48. Atmaca M, Kuloglu M, Tezcan E, Unal A. Efficacy of citalopram and moclobemide in patients with social phobia: Some preliminary findings. Hum Psychopharmacol. 2002;17:401-405.

49. Bouwer C, Stein DJ. Use of selective serotonin reuptake inhibitor citalopram in the treatment of generalized social phobia. $J$ Affect Disord. 1998;49:79-82.

50. Marazziti D, Dell'Osso L, Gemignani A, et al. Citalopram in refractory obsessive-compulsive disorder: An open study. Int Clin Psychopharmacol. 2001;16:215-219.

51. Leinonen E, Lepola U, Koponen H, Turtonen J, Wade A, Lehto H. Citalopram controls phobic symptoms in patients with panic disorder: Randomized controlled trial. J Psychiatry Neurosci. 2000;25:24-32.

52. Greist J, Chouinard G, DuBoffE, et al. Double-blind parallel comparison of three dosages of sertraline and placebo in outpatients with obsessivecompulsive disorder. Arch Gen Psychiatry. 1995;52:289-295.

53. Bogetto F, Albert U, Maina G. Sertraline treatment of obsessivecompulsive disorder: Efficacy and tolerability of a rapid titration regimen. Eur Neuropsychopharmacol. 2002;12:181-186.

54. Sousa MB, Isolan LR, Oliveira RR, Manfro GG, Cordioli AV. A randomized clinical trial of cognitive-behavioral group therapy and sertraline in the treatment of obsessive-compulsive disorder. $J$ Clin Psychiatry. 2006;67:1133-1139.

55. Liebowitz MR, DeMartinis NA, Weihs K, et al. Efficacy of sertraline in severe generalized social anxiety disorder: Results of a double-blind, placebo-controlled study. J Clin Psychiatry. 2003;64:785-792.

56. Van Ameringen MA, Lane RM, Bowen RC, et al. Sertraline treatment of generalized social phobia: A 20-week, double-blind, placebo-controlled study. Am J Psychiatry. 2001;158:275-281.
57. Walker JR, Van Ameringen MA, Swinson R, et al. Prevention of relapse in generalized social phobia: Results of a 24-week study in responders to 20 weeks of sertraline treatment. J Clin Psychiatry. 2000;20:636-644.

58. Chouinard G. Sertraline in the treatment of obsessive-compulsive disorder: Two double-blind, placebo-controlled studies. Int Clin Psychopharmacol. 1992;7 Suppl 2:S37-S41.

59. Koran LM, Hackett, E, Rubin A, Wolkow R, Robinson D. Efficacy of sertraline in the long-term treatment of obsessive-compulsive disorder. Am J Psychiatry. 2002;159:88-95.

60. Ninan PT, Koran LM, Kiev A, et al. High-dose sertraline strategy for nonresponders to acute treatment for obsessive-compulsive disorder: A multicenter double-blind trial. J Clin Psychiatry. 2006;67:15-22.

61. Albert U, Aguglia E, Maina G, Bogetto F. Venlafaxine versus clomipramine in the treatment of obsessive-compulsive disorder: A preliminary single-blind, 12 week, controlled study. J Clin Psychiatry. 2002;63:1004-1009.

62. Denys D, van der Wee N, van Megen HJ, Westenberg HG. A double-blind comparison of venlafaxine and paroxetine in obsessivecompulsive disorder. J Clin Psychopharmacol. 2003;23:568-575.

63. Denys D, van der Wee N, van Megen H Westenberg HG. A double-blind switch study of paroxetine and venlafaxine in obsessive-compulsive disorder. J Clin Psychiatry. 2004;65:37-43.

64. Phelps NJ, Cates ME. The role of venlafaxine in the treatment of obsessive compulsive disorder. Ann Pharmacother. 2005;39:136-140.

65. Rickels K, Mangano R, Khan A. A double-blind, placebo-controlled study of a flexible dose of venlafaxine ER in adult outpatients with generalized social anxiety disorder. J Clin Psychopharmacol. 2004;24:488-496.

66. Liebowitz MR, Gelenberg AJ, Munjack D. Venlafaxine extended release vs placebo and paroxetine in social anxiety disorder. Arch Gen Psychiatry. 2005;62:190-198.

67. Stein MB, Pollack MH, Bystitsky A, Kelsey JE, Mangano RM. Efficacy of low and higher dose extended-release venlafaxine in generalized social anxiety disorder: A 6-month randomized controlled trial. Psychopharmacology. 2005;177:280-288.

68. Dell'Osso B, Mundo E, Marazziti D, Altamura AC. Switching from serotonin reuptake inhibitors to duloxetine in patients with resistant obsessive compulsive-disorder: A case series. J Psychopharmacol. 2008;22:210-213.

69. Denys D. Pharmacotherapy of obsessive-compulsive disorder and obsessive-compulsive spectrum disorder. Psychiatr Clin North Am. 2006;29:553-584.

70. Stein DJ, Ipser JC, Baldwin DS, Bandelow B. Treatment of obsessivecompulsive disorder. CNS Spectrum. 2007;12 Supp1 3:S28-S35.

71. Pallanti S, Quercioli L. Treatment-refractory obsessive-compulsive disorder: Methodological issues, operational definitions and therapeutic lines. Prog Neuropsychopharmacol Biol Psychiatry. 2006;30:400-402.

72. Koran LM. Augmentation strategies for treatment resistant obsessivecompulsive disorder. Clin Neuropsychiatry. 2004;1:65-71.

73. Skapinakis P, Papatheodorou T, Mavreas V. Antipsychotic augmentation of serotoninergic antidepressants in treatment-resistant obsessivecompulsive disorder: A meta-analysis of the randomized controlled trials. Eur Neuropsychopharmacol. 2007;17:79-93.

74. Denys D, Fineberg N, Carey PD, Stein DJ. Quetiapine addition in obsessive-compulsive disorder: Is treatment outcome affected by type and dose of serotonin reuptake inhibitors. Biol Psychiatry. 2007;61:412-414.

75. Hollander E, Baldini Rossi N, Sood E, Pallanti S. Risperidone augmentation in treatment-resistant obsessive-compulsive disorder: A double-blind, placebo-controlled study. Int J Neuropsychopharmacol. 2003;6:397-401.

76. McDougle CJ, Epperson CN, Pelton GH, Wasylink S, Price LH. A double-blind, placebo-controlled study of risperidone addition in serotonin reuptake inhibitor-refractory obsessive-compulsive disorder. Arch Gen Psychiatry. 2000;57:794-801. 
77. Stein DJ, Bouwer C, Hawkridge S, Emsley RA. Risperidone augmentation of serotonin reuptake inhibitors in obsessive-compulsive and related disorders. J Clin Psychiatry. 1997;58:119-122.

78. Li X, May RS, Tolbert LC, Jackson WT, Flournoy JM, Baxter LR. Risperidone and haloperidol augmentation of serotonin reuptake inhibitors in refractory obsessive-compulsive disorder: A crossover study. J Clin Psychiatry. 2005;66:736-743.

79. Maina G, Pessina E, Albert U, Bogetto F. 8 week, single-blind, randomized trial comparing risperidone versus olanzapine augmentation of serotonin reuptake inhibitors in treatment-resistant obsessive-compulsive disorder. Eur Neuropsychopharmacol. 2008;18:364-372.

80. Yang KC, Su TP, Chou YH. Effectiveness of aripiprazole in treating obsessive compulsive symptoms. Prog Neuropsychopharmacol Biol Psychiatry. 2008;32:585-586.

81. da Rocha FF, Correa H. Successful augmentation with aripiprazole in clomipramine-refractory obsessive-compulsive disorder. Prog Neuropsychopharmacol Biol Psychiatry. 2007;31:1550-1551.

82. Weiss EL, Potenza MN, McDougle CJ, Epperson CN. Olanzapine addition in obsessive-compulsive disorder refractory to selective serotonin reuptake inhibitors: An open label case series. J Clin Psychiatry. 1999;60:524-527.

83. Koran LM, Ringold AL, Elliott MA. Olanzapine augmentation for treatment-resistant compulsive disorder. J Clin Psychiatry. 2000;61:514-517.

84. Bogetto F, Bellino S, Vaschetto P, Ziero S. Olanzapine augmentation of fluvoxamine-refractory obsessive-compulsive disorder (OCD): A 12 week-open trial. Psychiatry Res. 2000;96:91-98.

85. Bytrisky A, Ackerman DL, Rosen RM, et al. Augmentation of serotonin reuptake inhibitors in refractory obsessive-compulsive disorder using adjunctive olanzapine: A placebo-controlled trial. J Clin Psychiatry. 2004;65:565-568.

86. Carey PD, Vythilingum B, Seedat S, Muller JE, van Ameringen M, Stein DJ. Quetiapine augmentation of SRIs in treatment refractory obsessivecompulsive disorder: A double-blind, randomized, placebo-controlled study. BMC Psychiatry. 2005;5:5.

87. Fineberg NA, Sivakumaran T, Roberts A, Gale T. Adding quetiapine to SRI in treatment-resistant obsessive-compulsive disorder: A randomized controlled treatment study. Int Clin Psychopharmacol. 2005;20: 223-226.

88. Denys D, de Geus F, van Megen HJ, Westenberg HG. A double-blind, randomized, placebo-controlled trial of quetiapine addition in patients with obsessive-compulsive disorder refractory to serotonin reuptake inhibitors. J Clin Psychiatry. 2004;65:1040-1048.

89. Vulink NC, Denys D, Fluitman SB, Meinardi JC, Westenberg HG. Quetiapine augments the effect of citalopram in non refractory obsessive-compulsive disorder: A randomized, double-blind, placebo-controlled study of 76 patients. J Clin Psychiatry. 2009;70: 1001-1008

90. Abramowitz JS. Effectiveness of psychological and pharmacological treatment for obsessive-compulsive disorder: A quantitative review. $J$ Consult Clin Psychol. 1997;65:44-52.

91. van Balkom AJ, de Haan E, van Oppen P, Spinhoven P, Hoogduin KA, van Dyck R. Cognitive and behavioural therapies alone versus in combination with fluvoxamine in the treatment of obsessive compulsive disorder. J Nerv Ment Dis. 1998;186:492-499.

92. Marques Prazeres A, de Souza WF, Fontenelle LF. Cognitive-behavior therapy for obsessive-compulsive disorder: A systematic review of the last decade. Rev Bras Psiquiatr. 2007;29:262-270.

93. Kobak KA, Greit JH, Jefferson JW, Katzelnick DJ, Henk HJ. Behavioral versus pharmacological treatments of obsessive compulsive disorder: A meta-analysis. Psychopharmacology. 1998;136:205-216.

94. Perse T. Obsessive-compulsive disorder: A treatment review. J Clin Psychiatry. 1988;49:48-55.

95. Biondi M, Picardi A. Increased maintenance of obsessive-compulsive disorder remission after integrated serotoninergic treatment and cognitive psychotherapy compared with medication alone. Psychother Psychosom. 2005;74:123-128.
96. O'Connor KP, Aardema F, Robillard S, et al. Cognitive behaviour therapy and medication in the treatment of obsessive-compulsive disorder. Acta Psychiatr Scand. 2006;113:408-419.

97. Clark DM, Ehlers A, Hackmann A, et al. Cognitive therapy versus exposure and applied relaxation in social phobia: A randomized controlled trial. J Consult Clin Psychol. 2006;74:568-578.

98. Blomhoff S, Haug TT, Hellström K, et al. Randomized controlled general practice trial of sertraline, exposure therapy and combined treatment in generalized social phobia. Br J Psychiatry. 2001;179:23-30.

99. Liebowitz MR, Heimberg RG, Schneier FR, et al. Cognitive-behavioral group therapy versus phenelzine in social phobia: Long-term outcome. Depress Anxiety. 1999;10:89-98.

100. Blanco C, Heimberg RG, Schneier FR, et al. A placebo-controlled trial of phenelzine, cognitive behavioral group therapy, and their combination for social anxiety disorder. Arch Gen Psychiatry. 2010;67: 286-295.

101. Hollander E, Kwon JH, Stein DJ, Broatch J, Rowland CT, Himelein CA. Obsessive- compulsive and spectrum disorders: Overview and quality of life issues. J Clin Psychiatry. 1996;57 Suppl 8:3-6.

102. Foa EB, Grayson JB, Steketee GS, Doppelt HG, Turner RM, Latimer PR. Success and failure in the behavioural treatment of obsessive-compulsives. J Consult Clin Psychol. 1983;51:287-297.

103. Greist JH. Behavior therapy for obsessive-compulsive disorder. J Clin Psychiatry. 1994;55 Suppl:60-68.

104. Thoren P, Asberg M, Cronholm B, Jornestedt L, Traskman L. Clomipramine treatment of obsessive-compulsive disorder. A controlled clinical trial. Arch Gen Psychiatry. 1980;37:1281-1285.

105. Maina G, Albert U, Bogetto F. Relapses after discontinuation of drug associated with increased resistance to treatment in obsessivecompulsive disorder. Int Clin Psychopharmacol. 2001;16:33-38.

106. Diniz JB, Malavazzi DM, Fossaluza V, et al. Risk factors for early treatment discontinuation in patients with obsessive-compulsive disorder. Clinics (Sao Paolo). 2011;66:387-393.

107. Cottraux J, Mollard E, Bouvard M, Marks I. Exposure therapy, fluvoxamine, or combination treatment in obsessive-compulsive disorder: One year follow-up. Psychiatry Res. 1993;49:63-75.

108. Sapana R, Patel SR, Simpson HB. Patient preferences for obsessive-compulsive disorder treatment. J Clin Psychiatry. 2010;71:1434-1439.

109. Goodman WK, Price LH, Rasmussen SA, et al. The Yale-Brown Obsessive Compulsive Scale. I. Development, use, and reliability. Arch Gen Psychiatry. 1989;46:1006-1011.

110. Eisen JL, Phillips KA, Baer L, Beer DA, Atala KD, Rasmussen SA. The Brown Assessment of Beliefs Scale: Reliability and validity. Am J Psychiatry. 1998;155:102-108.

111. Alonso P, Menchon JM, Pifarre J. Long-term follow up and predictors of clinical outcome in obsessive-compulsive patients treated with serotonin reuptake inhibitors and behavioural therapy. $J$ Clin Psychopharmacol. 2001;62:535-540.

112. Black DW, Monahan P, Gable J, et al. Hoarding and treatment response in 38 nondepressed subjects with obsessive-compulsive disorder. J Clin Psychopharmacol. 1998;59:420-425.

113. Erzegovesi S, Cavallini MC, Cavedini P, et al. Clinical predictors of drug response in obsessive-compulsive disorder. J Clin Psychopharmacol. 2001;21:488-491.

114. Mundo E, Erzegovesi S, Bellosi L. Follow up of obsessivecompulsive patients treated with proserotoninergic agents. $J$ Clin Psychopharmacol. 1995;15:288-289.

115. Fontenelle LF, Mendlowic MV, Marques C, Versiani M. Early- and late-onset obsessive-compulsive disorder in adult patients: Exploratory clinical and therapeutic study. J Psychol Res. 2003;37:127-133.

116. Mataix-Cols D, Marks IM, Greist JH, Kobak KA, Baer L. Obsessivecompulsive symptom dimensions as predictors of compliance with and response to behaviour therapy: Results from a controlled trial. Psychother Psychosom. 2002;71:255-262.

117. Christensen DD, Greist JH. The challenge of obsessive-compulsive disorder hoarding. Prim Psychiatry. 2001;8:79-86. 
118. Mataix-Cols D, Rauch SL, Manzo PA, Jenike MA, Baer L. Use of factor-analyzed symptom dimensions to predict outcome with serotonin reuptake inhibitors and placebo in the treatment of obsessivecompulsive disorder. Am J Psychiatry. 1999;159:1409-1416.

119. Steketee G, Frost RO, Wincze J, Greene KAI, Douglass H. Group and individual treatment of compulsive hoarding: A pilot study. Behav Cognit Psychother. 2000;28:259-268.

120. Ferrão YA, Shavitt RG, Bedin NR, et al. Clinical feature associated to refractory obsessive compulsive disorder. J Affect Disord. 2006;94:199-209.

121. Hollander E, Bienstock CA, Koran LM, et al. Refractory obsessive-compulsive disorder: State-of-the-art treatment. J Clin Psychopharmacol. 2002;63 Suppl 6:20-29.

122. Catapano F, Sperandeo R, Perrris L, Lanzaro M, Maj M. Insight and resistance in patients with obsessive-compulsive disorder. Psychopathology. 2001;34:62-68.

123. Matzunaga H, Kiriike N, Matsui T, et al. Obsessive-compulsive disorder with poor insight. Compr Psychiatry. 2002;43:150-157.

124. Alonso P, Menchon JM, Segalas C, et al. Clinical implications of insight assessment in obsessive-compulsive disorder. Compr Psychiatry. 2008;49:305-312.

125. Foa EB, Abramowitz JS, Franklin ME, Kozak MJ. Feared consequences, fixity of belief, and treatment outcome in patients with obsessive-compulsive disorder. Behav Ther. 1999;30:717-724.
126. Himle JA, Van Etten ML, Janeck AS, Fischer DJ. Insight as a predictor of treatment outcome in behavioural group treatment for obsessivecompulsive disorder. Cogn Ther Res. 2006;30:661-666.

127. Catapano F, Perris F, Fabrazzo M, et al. Obsessive-compulsive disorder with poor insight: A three year prospective study. Prog Neuropsychopharmacol Biol Psychiatry. 2010;34:323-330.

128. Poyurovsky M, Faragian S, Pashinian A, et al. Clinical characteristics of schizotypal-related obsessive-compulsive disorder. Psychiatry Res. 2008;159:254-258.

129. Ravi Kishore V, Samar R, Janardhan Reddy YC, Chandrasekhar CR, Thennarasu K. Clinical characteristics and treatment response in poor and good insight obsessive-compulsive disorder. Eur Psychiatry. 2004;19:202-208.

130. Turksoy N, Tukel R, Ozdemir O, Karali A. Comparison of clinical characteristics in good and poor insight obsessive-compulsive disorder. J Anxiety Disord. 2002;16:413-423.

131. Lelliot PT, Noshirvani HF, Basoglu M, Marks IM, Monteiro WDL. Obsessive-compulsive beliefs and treatment outcome. Psychol Med. 1988;18:697-702.

132. Sobin C, Blundell ML, Weiller F, Gavigan C, Haiman C, Karayiorgou M. Evidence of a schizotypy subtype in OCD. J Psychiatry Res. 2000;34:15-24.
Neuropsychiatric Disease and Treatment

\section{Publish your work in this journal}

Neuropsychiatric Disease and Treatment is an international, peerreviewed journal of clinical therapeutics and pharmacology focusing on concise rapid reporting of clinical or pre-clinical studies on a range of neuropsychiatric and neurological disorders. This journal is indexed on PubMed Central, the 'PsycINFO' database and CAS, and is the official

\section{Dovepress}

journal of The International Neuropsychiatric Association (INA). The manuscript management system is completely online and includes a very quick and fair peer-review system, which is all easy to use. Visit $\mathrm{http}: / /$ www.dovepress.com/testimonials.php to read real quotes from published authors. 